\title{
Case study on the effects of a disability inclusive mindset in a large biotechnology company
}

Effects of a disability inclusive mindset

Chase Ochrach

Counseling Psychology, University of Wisconsin-Madison, Madison, Wisconsin, USA

Kathryn Thomas

Yale School of Medicine, New Haven, Connecticut, USA

Brian Phillips

Rehabilitation Psychology, Utah State University, Logan, Utah, USA, and

Ngonidzashe Mpofu, Tim Tansey and Stacie Castillo

Rehabilitation Psychology, University of Wisconsin-Madison, Madison,

Wisconsin, USA

\begin{abstract}
Purpose - Employers increasingly seek a competitive advantage through inclusive hiring practices and recruitment of persons with disabilities. Early research indicates when employers consider individuals for their strengths rather than solely for their needs, the organization prospers. However, details about how companies pursue a disability inclusive workplace and the effect of those efforts are poorly understood.

Design/methodology/approach - An inductive qualitative case study approach was utilized to understand one biotechnology corporation and their approach to recruiting, hiring, and retaining employees with disabilities. Individual and focus group interviews were conducted.

Findings - Results suggest that when the company lives its mission around wellness and inclusivity, they benefit from working with and learning from a range of perspectives, furthering their growth. Placing equal emphasis on hiring a diverse workforce and prioritizing supports and wellness practices lead to greater productivity and innovation.

Practical implications - This study illustrates how one company successfully recruits and hires persons with disabilities, resulting in benefits to their financial bottom line and to the organizational culture.

Originality/value - This paper offers insights for other companies intentionally hiring persons with disabilities, providing accommodations in the workplace, and creating an organizational culture where all employees feel valued and supported. These steps have a direct impact on employee engagement, productivity, and retention.
\end{abstract}

Keywords Case study, Diversity initiative, Inclusivity, Recruitment, Employees with disabilities

Paper type Case study

\section{Introduction}

Employers increasingly recognize the benefits to productivity and organizational culture resulting from hiring persons with disabilities (PWDs) (Lindsay et al., 2018). Approximately

(C) Chase Ochrach, Kathryn Thomas, Brian Phillips, Ngonidzashe Mpofu, Tim Tansey and Stacie Castillo. Published in Journal of Work-Applied Management. Published by Emerald Publishing Limited. This article is published under the Creative Commons Attribution (CC BY 4.0) licence. Anyone may reproduce, distribute, translate and create derivative works of this article (for both commercial and noncommercial purposes), subject to full attribution to the original publication and authors. The full terms of this licence may be seen at http://creativecommons.org/licences/by/4.0/legalcode

Preparation of this manuscript was supported in part by the National Institute on Disability, Independent Living, and Rehabilitation Research through Grant \# HHS-2016-ACL-NIDILRR-RT-0138 to Virginia Commonwealth University, Rehabilitation Research and Training Center on Employer Practices. The opinions expressed herein do not necessarily reflect the endorsement or position of the U.S. Department of Health and Human Services.

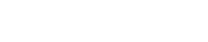


JWAM

14,1

114

$26 \%$ of people in the United States live with one or more of six functional types of disability, including cognitive, hearing, mobility, vision, self-care or independent living-related (Centers for Disease Control and Prevention, 2018). Representing just over $25 \%$ of the US population, PWDs compose a large and valuable pool of current and potential members of the US workforce. However, PWDs continue to face challenges finding gainful employment in the United States, such that PWDs have an unemployment rate more than twice that of people without a disability (US Bureau of Labor Statistics, 2020).

This lack of representation signals a significant problem of missed opportunity, as disability-inclusive hiring practices have been associated with improved productivity at the employee and organizational level (Tompa et al., 2021). One potential method of increasing rates of employment for PWDs is by increasing companies' awareness of the how much PWDs can contribute to the workforce, particularly in companies that maintain a disabilityinclusive mindset (Lindsay et al., 2018). Companies with a disability-inclusive mindset go beyond maintaining the minimum legal requirement of anti-discrimination laws to create a disability-inclusive culture in all their thinking, policies, and operations. Such companies proactively focus on making the necessary changes needed to identify and remove barriers to full workplace participation for PWDs, including the removal of physical, communication, and attitudinal barriers (CDC, 2020). This kind of mindset is represented by the concept of customized employment, which encourages organizations to customize the relationship between employee and employer based on the individual strengths and needs of both parties (Inge, 2006). Despite several studies demonstrating the benefits of an inclusive culture and workforce at the individual, organizational, and societal level (Tompa et al., 2021) a specific roadmap for implementing this type of corporate culture remains elusive.

According to Weick's (1979) organizational information theory, people in organizations play active roles as creators of their environment through interpretation of information on a systemic level. Specifically, Weick (1979) emphasized the importance a company engaging in ongoing sensemaking, which is the process of rendering meaning from experience and constructing order out of disorder (Patriotta, 2016). Within a company, sensemaking is a reciprocal relationship, such that individuals both create and are influenced by their organizational environment (Weick, 1979). By focusing on communication from both topdown and bottom-up perspectives within a company, sensemaking provides a method of promoting disability-inclusive mindsets through centralized communication and information processing within a company (Glynn and Watkiss, 2020; Weick, 1979). Weick conceptualizes sensemaking as central to organizing around a common mission and goal (Weick, 2005). This theory is utilized in the current study by highlighting how a common organizational mission can allow employees across departments to make sense of their role in the company and of the company's role in the community. By engaging in the sensemaking process, leaders of companies can create a disability-inclusive mindset that influences the company culture on all levels to remove barriers and promote inclusive policy and culture for the hiring and retention of PWDs. Weick's theory applies to this case in that the way the organization and its members make sense and meaning of their work through identifying with the organization's inclusive mission and commitment to diversity. Previous studies have applied Weick's theory to various aspects of organization and management (Tsoukas et al., 2020), including process research (Langley et al., 2013) and organizational cognition (Eden and Spender, 1998), among others. We extend findings from these and other previous studies to understand how sensemaking as a process furthers mission-based practices centered on diversity and inclusion.

Companies are increasingly moving to appreciate disability inclusion as a valuable contributor to diversity in the workplace (Gilbride, et al., 2003; Padkapayeva et al., 2017). Research has revealed that companies identify several benefits to employing PWDs, including an expanded hiring pool, positive psychosocial impacts of retention of PWDs on 
employees with or without disabilities, and increased diversity of the workplace (CDC, 2020; Lindsay et al., 2018). By modifying recruitment and retention strategies, developing disability inclusion mediations, personalizing workplace and workspace modifications for PWDs, and matching the needs and skills of PWDs with the needs of the company, company leadership and human resources (HR) professionals can create disability inclusive mindsets by creating positive social attitudes regarding hiring PWDs (Gilbride et al., 2003; Padkapayeva et al., 2017).

Research has also suggested that employee job fit, company culture, and previous employer experience with hiring PWDs all increase recruitment and retention of PWDs, which in turn shapes future HR hiring practices and the assumption of inclusive attitudes and perspectives company-wide (Gilbride et al., 2003). This aligns with findings that companies that reflect on their own practices, learn from their past organizational choices, and adapt to the internal and external environment are more sustainable in the long-term (Fam et al., 2017; Fergusson et al., 2020). Additionally, HR employees with a higher degree of social awareness can increase the pace at which PWDs are recruited as well as the pace at which exposurebased disability-inclusive mindsets are encouraged in the workplace (Chan et al., 2010). This is especially important considering the growing centrality of social consciousness in what attracts new employees to work for organizations, underscoring the overall sustainability of that organization (Brockhaus et al., 2017; Rimanoczy and Pearson, 2010). Employing PWDs tends to decrease employer misconceptions, such as the idea that PWDs are not seeking work or are not qualified for company positions (Bonaccio et al., 2020). Employing PWDs has been shown to increase future hiring and retention of job applicants with disabilities resulting in increased integration of workers with disabilities, development of disability-inclusive workplaces, and more sustainable futures for employees and organizations (Bonaccio et al., 2020; Fergusson et al., 2020). These and other recent studies illustrate the unique benefits to hiring persons with disabilities, yet few offer a specific roadmap for how to actively recruit and hire PWDs and provide individualized accommodations to allow them, and the organization as a whole, to be successful. The current paper attempts to offer tangible suggestions through the illustration of one mid-sized company's successful implementation of a disability-inclusive mission and practices.

This paper is structured as follows. The first section outlines the methods used in this study, which is an inductive case study of one company's approach to hiring and retainment of PWDs. The organization and its specific subdivisions involved in the recruitment, hiring, and retainment of PWDs are described. The results of the study are then outlined, highlighting the company's mission and values, the actual inclusivity practices employed, and the impacts of these practices. The next section of the paper discusses the main findings of the study and connects those findings to existing research on PWDs in the workplace and general organizational culture. In this study, it was found that recruiting, hiring, and supporting PWDs in the workplace resulted in more workplace diversity, a willingness to provide accommodations for all employees, positive corporate climate, and increased productivity. Thus, this paper contributes evidence in support of the positive impacts of initiatives for hiring PWDs on employees, including PWDs, as well as the organization as a whole.

\section{Methods}

The purpose of this study was to implement an in-depth case study of a biotechnology company that has expressed commitment to inclusive hiring and retainment and a clear recognition of the company-wide benefits of hiring PWDs. We hoped to understand more about the company's mission and values and how these values translate into policy and action that supports hiring, retaining, and supporting all employees, including PWDs. This 
JWAM

14,1

study was guided by the following questions: (1) What are the overarching attitudes, values, and approaches taken by this company in their efforts to be inclusive and diverse? And, (2) How does this company extend their message of wellbeing and support throughout all levels and departments of the company?

Given the formative nature of this investigation, we used a qualitative case study design that allowed for exploration of events or phenomena from multiple sources, with the purpose of looking into the unique experience of the people's lives and interactions with the environment (Corbin and Strauss, 2015). This inductive qualitative design allowed for an open evaluation of the complexities and considerations involved in recruiting, hiring, supporting and retaining PWDs through in-depth interviews with multiple staff members at different levels within the company (Maxwell, 1996). Interviews and focus groups were utilized to gain an open, in-depth understanding of employees' beliefs and experiences which was essential to informing our qualitative inquiry (Gill et al., 2008). As this investigation is exploratory in nature and our aim is to place greatest emphasis on the voices of our participants, a qualitative approach was necessary (Miles and Huberman, 1994). The research team involved in data collection and analysis was comprised of six rehabilitation psychology faculty and doctoral students across three universities in the United States. Team members discussed potential biases prior to engaging in data collection and again before completing the analysis to reduce the potential for biases to influence the results.

\section{Organization}

The subject of this study is a large biotechnology company centralized in the Midwest. This company has been recognized as a Great Place to Work-Certified ${ }^{\mathrm{TM}}$ company, meaning they have been independently evaluated by the third party and recognized for having a positive workplace culture.

Organizational structure. This biotechnology company was described as using a Matrix Organization style where managerial teams spanned different units within the company (Galbraith, 1971). The HR director noted this as key to maintaining priority on employee retention across all units. Part of the company's success in supporting and accommodating their employees was attributed to the division of responsibility within the company. Rather than processing all accommodations requests through a general HR team, their approach involved multiple specialized teams working together to recruit and retain employees. These included teams focused on (1) Recruitment, (2) Wellness, (3) Leaves and Accommodations, (4) Business Partners, and until recently (5) Security, which aligned under another unit in the organization.

The Leaves and Accommodations team has a lead role in processing accommodation requests while also ensuring that all employees and teams are aware of the potential for accommodations and how to use them. As one employee described, "I did not know until I received that initial email that we do have the entire accommodations team. They can reach out if you need anything." The Business Partners act as the HR representatives across each unit in the company (e.g., the clinical lab). Business Partners were said by the HR director to play a key role in informing the HR team of needs within a particular unit while also ensuring that the company culture, priorities, and values extends to each unit. The Security team, although no longer part of $\mathrm{HR}$, continue to fill several roles in the company, including acting as first responder for physical and mental health needs. These teams do not want the onus to always be on employees but seek to preemptively act in providing support by assessing potential problems within the company's various departments and teams.

\section{Procedures}

Researchers worked with state employment agencies to identify companies with a reputation for inclusive disability hiring. Once identified as a company of interest, the 
research team worked closely with leadership from the biotechnology company to organize a site visit and to conduct interviews and focus groups. Prior to the site visit, the research team requested access to any written information, forms, or documents relevant to their disability efforts (e.g., company policies). Key personnel were also asked to provide a few written answers regarding the implementation of practices and policies related to their disability initiative. These were reviewed by the research team prior to the site visit in order to allow for better understanding of company activities prior to conducting interviews and focus groups. Researchers met on the day of the site visit to discuss potential biases and strategize how these biases could be minimized. The present study consisted of interviews with the director of human resources (HR) as well as members of the teams responsible for recruiting and for providing accommodations. A focus group was held with four direct-line supervisors and another with seven current employees, some of whom identified as having a disability that significantly impacted their work. All interviews were conducted in person at the company headquarters in the Midwest. Interviews and focus groups were complimented by information obtained through on-site observation, company policies and other written materials, the company website, and a climate survey described in the measures section below. A tour of the facility with an emphasis on any disability-related environmental adjustments, modifications, or supports helped inform data collection and analysis. The interviews and site tour led to the collection of more written policies and procedures that were added to the materials for analysis.

Focus groups and interviews ranged from 20 to $90 \mathrm{~min}$ in length. All interviews and focus groups were completed with two members of the research team present, serving to reduce to the possibility of interviewer bias while also enriching the data collection process with multiple perspectives. Audio recordings of all interviews and focus groups were later transcribed for analysis. Approval from the university's Institutional Review Board was also obtained to conduct this study with human subjects, and informed consent was obtained from all participants.

\section{Measures}

In addition to the on-site observations of the research team, a climate and policy checklist was used to assess the different disability-related aspects of the company during the postsite visit analysis of data. This checklist consisted of 70 disability-related policies or practices that were marked as being present or not present in the company. The semistructured interviews and focus groups conducted on-site included primarily open-ended questions addressing the recruitment, hiring, integrating, and retaining workers with disabilities. The interviewees were asked to reflect on the company's practices and policies that were intended to create an inclusive environment for workers with disabilities and the results of these efforts.

\section{Data analysis}

All data sources were reviewed and coded by two coders before coming to consensus on the major themes and insights. Interview and focus group transcripts were read by each coder initially and data were categorized into practical and mindset themes. Further categories were determined by grouping data into subthemes, including a focus on inclusive practice, supportive climate, emphasis on retainment, and being mission driven. In the event of a disagreement between two coders, a third coder was included to discuss the item until an agreement was reached. Once created, the coding and narrative of the case study were brought to the larger research team for a community-based approach to refining and improving the accuracy of the case study.

\section{Effects of a disability inclusive mindset}




\section{JWAM \\ 14,1}

\section{Results}

This case study focuses on the inclusive hiring and retention practices of a large biotechnology company and the perceived impact of these efforts. In contrast to many other disability diversity case studies, this was not focused on a disability program but rather on capturing a company culture focused on seeking to make disability inclusivity part of all that they do. Results emerged from data collected over several months of 2019 and include analysis across individual and group interviews as well as on-site observation, the climate survey, and written policies (e.g. employee handbook, Autism Workforce guide). Results are broken down into the following categories: (1) Company Mission and Mindset, (2) Disability Inclusive Practices, which include both hiring and retention practices, and (3) Impact of Inclusive Practices. We proceed with a review of each category and their domains.

\section{Company Mission and Mindset}

An overarching theme noted throughout the interviews, whether senior management or recent hire to work in the lab, was the sense of the company's value-driven mission. An internal document describing the company Wellness program provided a Vision Statement that captures the ethos of their mission: "We believe our employees are our most valuable resource and through educating and encouraging the health and well-being of our employees, we in turn can achieve a higher level of patient care." Throughout every interview and every evaluation of the company's organizational documentation and structure, this mission-driven focus emerged. As a member of the Leaves and Accommodations team stated, "We live our mission statement here, whereas other companies have a mission statement. And it's getting everyone on board from top down to have an environment of support." Multiple members of the management team noted that this sense of mission did not happen by accident or stem from policy alone but was the result of embedding themselves within departments and consistently communicating those core values. Of their role, one manager stated, "We're out there being that kind of culture keeper."

Their value-driven mission emphasized an inclusive mindset that was shared throughout the company and from recruitment to retirement. An employee with a disability stated, "I feel like they really preach diversity and they show it in their actions. The last company I worked for, one of their core values was diversity, but it wasn't really. They were not accommodating to anything at all." The worker went on to say, "It is just comfortable to know that my job is secure, and they really care about our well-being." This inclusive mindset aligned with and overshadowed the emphasis on legal requirement relating to discrimination. A member of the management team stated, "I think we go above and beyond what's required under the ADA (Americans with Disabilities Act 2008). The ADA is pretty bare minimum for a human being at work." Speaking to this point, another manager stated,

The first question a lot of companies will ask is, "Are we legally required to do this?" Which is a fine question. It's a valid question because you want to make sure that you're doing everything legally. But I feel like [company's] first question, because we already know we're in legal compliance across the board for Leaves and Accommodations is, "Why not?" and "What can we do?"

Multiple people noted that efforts to infuse these values throughout the company begins from company leadership. The manager overseeing employee leave and accommodations stated in relation to making necessary accommodations, "We have the support of everyone higher up and, without that support, I do not think it would be as successful." The head of HR spoke to this point, saying,

I think it starts with that commitment that we want to be an inclusive workforce, but you cannot always anticipate what that is going to mean for the next person who walks through your door. I 
think if you're coming at it with that yes mindset... You know if you start there, you can usually find a way to make it work.

She continued,

You're not asking all of your employees to fit one exact requirement, once you're thinking, "What do they need?" and "How do they learn?" ... just the mindset of how to help them be successful here, "What does that mean for them?" That's a real shift from, "I'm the boss, and this is how it works here."

\section{Disability Inclusive Practices}

The mission and mindset of the company produced a number of inclusive practices that could be categorized into hiring, retention or some combination of the two.

Inclusive hiring practices. The director of HR spoke to the company's consideration of community in shaping their hiring practices and performance saying, "We look for partnerships with different organizations, both because we want to be a good partner and because of the organization's being really good conduits for people looking for work." Another manager emphasized the importance they place on partnering with specific government and non-profit agencies aimed at improving the education and employment of diverse members of the local community and organizations in the area.

Speaking to the inclusive mindset that fuels this biotechnology company, an HR manager spoke of how they work with applicants saying, "whether there's a disability or not, our team approaches these interviews with the same level of fairness and equality. And I think that's become just part of the [company's] DNA." Part of this DNA, or inclusive mindset, was noted to stem from their resources to work with a diverse workforce. The HR manager continued by saying applicants with disabilities "do not even phase our hiring team now because we are so used to the support we get from our Leaves and Accommodation team."

Inclusive retention practices. The emphasis on retaining employees was consistent across all collected information. Multiple HR management spoke of viewing employees as being in long-term careers when hiring on with the company. Employees seem to get the message with one stating, "We heard management talk about wanting to create careers," in contrast to what the employee described experiencing in other companies as being used for a couple of years. Two methods employed for fostering this career mentality were supporting employees in pursuit of upward movement and facilitating employee engagement within the company. Leadership emphasized providing employees with what they need to be successful, including a change in position or environment when needed. An HR director reported the mutual benefit of this approach by saying, "I am a firm believer that culture and engagement of employees has a very positive effect on revenue, on your total growth as an organization. If we were constantly replacing people, that would be a big time and money sinkhole." He concluded that recruiting for diversity and then "giving them the tools and the support to really be successful" benefits all.

Inclusive retention practices were often very individually based. One frontline supervisor said, "I do not have any accommodation that's exactly like the other. The [Leaves and Accommodation Team] really tailor to the individual." A member of the Recruitment team emphasized the importance of getting the employee's perspective when addressing accommodation needs stating, "It might not be something that our team is familiar with, but we get familiar with it really quickly."

The company's retention practices include a strong teaching and training component, with training focused on educating both the employees with disabilities and their supervisors. Regarding employee training, the Director of HR said that part of the company's retention practices include
Effects of a disability inclusive mindset 
JWAM

14,1

creating a welcoming environment and teaching people what it's like to work here... The first step is really that inclusive culture of teaching and recognizing that people are coming from different places and at different levels of their readiness in order to actually hit the floor for their job.

Regarding supervisor training, an HR director described the Family and Medical Leave Act (FMLA) and ADA training they provide to supervisors, with the comment that "We do not ask [supervisors] to understand all of the intricacies of it. What we do want them to understand through the training is to be receptive." Multiple supervisors described the trainings with appreciation for their thoroughness and for the support that was available to them, as captured by the supervisor who stated, "There's [a training] for the inclusive workplace, which is wonderful training." This supervisor continued, "The fact that they even do that is impressive to me." It was noted across interviews that providing the trainings in multiple formats (audio-video, written, etc.) was appreciated by supervisors and employees with disabilities alike.

The company was noted for taking a proactive approach to accommodations as part of their retention efforts. One employee shared his experience saying, "Because I identified with a disability through the onboarding process, probably within a week or two from hire, I got an email saying, "Hey, you identified with a disability. Are there any accommodations that we can provide?" Another employee described their supervisor's approach to accommodations after having already been with the company, reporting, "When I started in the lab, I never knew how physical that was. It was actually my supervisor that pulled me aside and said, 'You know, we have accommodations and we can help you through this."'

\section{Inclusivity as organizational identity: impact of Inclusive Practices}

Although frontline supervisors tasked with balancing performance with employee flexibility described the intersection as straining at times, the overwhelming majority of staff perceptions of the company's inclusivity efforts were positive. Staff reported beneficial impacts that ranged from company performance, to employee retention, to improved perceptions of the company. Although not easily quantified, several staff expressed their belief that the mission, mindset, and inclusive practices described served to improve overall company performance. For instance, the director of HR stated,

I would absolutely say that it's a benefit ... By recruiting a diverse population and then giving them the tools and the support to really be successful, that goes a really long way towards engagement and culture, and that certainly has direct impact on the bottom line.

Another manager talked of how providing employee accommodations according to their need improved performance and retention. A front-line supervisor spoke of an employee who was about to be terminated for poor performance. In one of the final meetings before termination, the employee disclosed a hidden disability that had been affecting their work performance. Accommodations were put in place and the employee retained their position through strong performance.

Management and supervisors both spoke to the importance of increasing the diversity in thought that produced insights, understanding, and openness. As an HR Director explained,

Through working with [PWDs], we've found some of the things that we offer would actually be good to offer to a broader population as well. If we are looking at different ways of learning, different ways of training, for instance, even if somebody has not self-identified as having a disability, we all learn differently ... Personally, I think that it gives you a more open mindset, things that I had not considered before.

The most common response related back to employee perceptions of the company. Employees shared a sense of purpose and pride in the company's efforts to create a disability- 
friendly work environment. One HR manager spoke to this point saying, "I do not know that it affects me, but it makes me feel good about the company I work for. I'm proud of that. I think it's important and I think it speaks to the authenticity of our values." Another manager stated,

I think there's an effect on morale ... We get a lot of really positive feedback about the diversity of our team. A lot of people who choose to work at [company], I find that a big driver behind their decision to work here is because they have a personal connection to our mission. They feel good about working for a company that offers these accommodations for their colleagues and coworkers. They can see people of different abilities working in different ways towards the same mission.

These positive perceptions often connected directly to job satisfaction and a desire to stay with the company. A front-line supervisor said, "I think it helps us retain the employees who truly want to be here ... and helps us keep really talented people." One employee with a disability stated that she is quick to tell her friends and acquaintances to work at this company. She continued, "If you're looking to improve your life, apply." More seriously, another employee with a disability described being made fun of at her previous company and how refreshing it was to be able to trust that she would be treated respectfully at this biotechnology company. One of the strongest statements on the retention efforts of the company came from an employee who talked of switching from his partner's health insurance for the first time in years because of the stability he felt in his work. He stated with a tone of pride, "I'm actually going to be taking over the insurance because I feel comfortable here."

\section{Discussion}

Workplace challenges faced by PWDs result from the intersection of individual needs, societal structures, and employer initiatives, policies, and procedures that influence company culture (Chan et al., 2010). One way to minimize workplace experiences of discrimination and invalidation for PWDs is for companies to actively value diversity and inclusivity in mission, mindset, and policies through organizational sensemaking. By engaging in ongoing sensemaking, companies can allow for individuals to promote disability-inclusive mindsets by both creating and influencing their organizational environment (Weick, 1979; Glynn and Watkiss, 2020). The company at the center of this study specifically organizes their work around the central mission of disability-inclusivity and overarching support and accommodations for all-a common mission through which, as was shared in interviews, employees make meaning of their work. As meaning-making is a human-driven process, this study illuminates how Weick's theory of organizational information can explain the practical implications of organizing a corporate culture around a common goal (Tsoukas et al., 2020). This approach recognizes PWDs as assets as companies provide them with the supports needed to be successful. Such efforts uplift the individual employee and the company-wide productivity and culture (Lindsay et al., 2018). This company offers a useful model for other companies looking to implement a disability-inclusive approach that values the contributions of all employees.

\section{Organizational culture as a reciprocal process}

Interview participants made it clear that this company values a sense of connectedness and reciprocal respect among team members. Weick (1979) suggests that organizations and those belonging to them experience a reciprocal relationship - that is, individuals both create and are influenced by their organizational environment through the process of sensemaking. This proposition suggests that general organizational attitudes (such as prioritizing inclusivity and diversity in the workplace) must be fed through both top-down and bottom-up pathways. Weick further suggests that the way members of an organization make sense of experiences informs organizational action in a recursive process. This sensemaking process is often 
JWAM

14,1 equally cognitive and emotional (Mikkelsen et al., 2020) and can stretch from broad, companywide search for meaning to the minutiae of even the language used by an organization (Bakken and Hernes, 2006).

Using this framework, the company at the center of this study appears to make opportunistic sense of diversity, seeing PWDs as introducing unique skills, perspectives and talents to the company. This sensemaking process is likely driven both by a recognition of the overall productivity and economic benefits as well as employees' emotional investment in the value of working alongside and learning from diverse team members. The development of an organizational culture and mission is more recursive than linear where both meaning and action influence sensemaking and contribute to the ultimate climate (Glynn and Watkiss, 2020). The company as a whole and the individual employees reciprocally influence each other in terms of company values, productivity, and inclusive culture. This organization clearly benefits from such symbolic interactionism, as interviews with employees and management revealed an unequivocal emphasis placed on supporting and being supported by employees with disabilities.

\section{Dedication to morale and community}

Staff and leaders both reported a felt sense of community and a dedication to elevating morale throughout this company. It seems that promoting a sense of connectedness and support fosters positive attitudes, productivity, and customer service for this mid-sized organization. Some researchers suggest that leaders can improve productivity, employee relations, and talent development when they align their actions with valuing a diverse workforce (Hughes, 2016). Thus, fostering acceptance, support, and growth for diverse employees is fundamental to prosperous relationships internally and externally for the organization.

Previous findings suggest that high levels of cohesion among members of a group may predict performance (Gammage et al., 2001). Additional research suggests when a group agrees on the same organizational goals, they subsequently experience higher rates of group drive, cohesion, and productivity (Greene, 1989). This is apparent in the current case, as interview participants reported feeling the congruence with the company goals of commitment to customer service and valuing and supporting team members.

\section{How to replicate elsewhere}

Interviews with company employees and administrators included asking about ways other companies could emulate the company's approach to recruiting, hiring, and retaining PWDs. The Leaves and Accommodations team had several suggestions for how organizations should be approaching diversity and inclusivity. One member of this team stated,

It's deciding as a company, "Are you going to be willing to go that much further for the employee to go above and beyond what the federal government is asking you to do?" But it is completely replicable if you desire that for your company.

This and other statements shared in the focus group interviews clearly suggest that the starting point for companies thinking about improving their disability diversity efforts is whether they want to go beyond the minimum standards required by law to create a truly inclusive work culture. An open stance of curiosity seems to be another great starting point for companies hoping to emulate this biotechnology company's approach. Multiple members of the Leaves and Accommodations team commented on being willing to ask questions and listen to the needs of employees, rather than responding only to the requests brought to their attention. This open stance was reiterated by an HR director, who saw it as going hand in hand with the company's organizational goal of learning alongside their employees. The HR director stated, 
I think it starts with that commitment to be an inclusive workforce ... But you cannot always anticipate what that is going to mean (The next person who walks through your door, what might they need to be successful?). It is not necessarily something that I think every organization wants to do.

The HR director also encouraged companies to think about their employees in terms of their unique value rather than their ability to fit the model of the organizations' values. Overall, this biotechnology company's employees and administrators seemed optimistic about the possibility of their model, philosophy, and approach to hiring and recruitment to be replicated elsewhere. This approach becomes possible through a stance of curiosity, a willingness to learn, and approaching each potential employee as having a unique skillset and worldview.

\section{Conclusions and implications}

The current study illustrates that consistent company-wide communication and sensemaking can lead to a disability-inclusive mindset that promotes valuing, supporting, and retaining employees with disabilities (Weick, 1979; Glynn and Watkiss, 2020). This midsized biotechnology company chooses to prioritize employee well-being by offering supports and accommodations for all employees regardless of ability status. A bidirectional relationship was identified, where company directors recognized the value in supporting employees, which reduces staff turnover and improves company climate. This company demonstrates a clear person-first focus in how they recruit, hire, and retain diverse employees, especially PWDs. This focus was reiterated through interviews as participants described a sense of connectedness to one another and to the organizational mission more broadly. Additionally, findings from this case study suggest that creating specific company teams to focus on providing accommodations, promoting wellness and safety, and facilitating leave for employees promotes employee well-being and leads employees to feel that their needs are being met. Ultimately, a top-down focus on inclusivity led to a consistent sense of meaning and values across all levels of the company, thus providing an example of how companies can value and provide diversity, support, and inclusion to employees when both a company-wide attitude and specific policies and practices are implemented. In alignment with Weick's theory, the process of sensemaking from top-down and bottom-up directions in the company were both driven by a common commitment to inclusivity a positive work experience for all (Weick, 1979, 2005). A number of insights emerged from this study that may be utilized to the advantage of managers and human resources personnel:

(1) Intentionally recruiting, hiring, and retaining PWDs in the workplace increases the diversity of perspectives in the workplace and positively impacts the company bottom line;

(2) Successful outcomes from a company-wide diversity and inclusivity initiative results from both top-down and bottom-up implementational commitment; and

(3) Increasing corporate diversity through this kind of initiative has a positive effect on employee attitudes and engagement and the overall corporate climate.

\section{References}

Americans with Disabilities Act Amendments Act, 42 U.S.C. Ch. $126 \S 12101$ (2008).

Bakken, T. and Hernes, T. (2006), "Organizing is both a verb and a noun: weick meets Whitehead", Organization Studies, Vol. 27 No. 11, pp. 1599-1616.

Bonaccio, S., Connelly, C.E., Gellatly, I.R., Jetha, A. and Ginis, K.M. (2020), “The participation of people with disabilities in the workplace across the employment cycle: employer concerns and research 
JWAM

14,1 evidence", Journal of Business and Psychology, Vol. 35, pp. 135-158, doi: 10.1007/s10869-0189602-5.

Brockhaus, S., Fawcett, S.E., Knemeyer, A.M. and Fawcett, A.M. (2017), "Motivations for environmental and social consciousness: reevaluating the sustainability-based view", Journal of Cleaner Production, Vol. 143, pp. 933-947.

Centers for Disease Control and Prevention (2018), "Disability and health data systems (DHDS)", available at: https://www.cdc.gov/ncbddd/disabilityandhealth/dhds/index.html?CDC_AA_ refVal $=$ https $\% 3 \mathrm{~A} \% 2 \mathrm{~F} \% 2 \mathrm{Fwww} . c d c . g o v \% 2 \mathrm{Fncbddd} \% 2 \mathrm{Fdisabilityandhealth} \% 2 \mathrm{Fdhds}$.html (accessed 1 June 2020).

Centers for Disease Control and Prevention (2020), "Disability and health inclusion strategies", available at: https://www.cdc.gov/ncbddd/disabilityandhealth/disability-strategies.html (accessed 5 June 2020).

Chan, F., Strauser, D., Maher, P., Lee, E., Jones, R. and Johnson, E.T. (2010), "Demand-side factors related to employment of people with disabilities: a survey of employers in the Midwest region of the United States", Journal of Occupational Rehabilitation, Vol. 20 No. 4, pp. 412-419, doi: 10. 1007/s10926-010-9252-6.

Corbin, J. and Strauss, A. (2015), Basics of Qualitative Research: Techniques and Procedures for Developing Grounded Theory, 4th ed., Sage Publications, Newbury Park, CA.

Eden, C. and Spender, J.-C. (1998), Managerial and Organizational Cognition, Sage, London.

(2017), in Fam, D., Palmer, J., Riedy, C. and Mitchell, C. (Eds), Transdisciplinary Research and Practice for Sustainability Outcomes, Routledge, New York, NY.

Fergusson, L., van der Laan, L., Shallies, B. and Baird, M. (2020), "Work, resilience and sustainable futures: the approach of work-based research to problems and their solutions", Journal of WorkApplied Management, Vol. 12 No. 1, pp. 22-41.

Galbraith, J.R. (1971), "Matrix organization designs: how to combine functional and project forms", Business Horizons, Vol. 14 No. 1, pp. 29-40, doi: 10.1016/0007-6813(71)90037-1.

Gammage, K.L., Carron, A.V. and Estabrooks, P.A. (2001), "Team cohesion and individual productivity: the influence of the norm for productivity and the identifiability of individual effort”, Small Group Research, Vol. 32 No. 1, pp. 3-18.

Gilbride, D., Stensrud, R., Vandergoot, D. and Golden, K. (2003), "Work environments and employers open to hiring and accommodating people with disabilities", Rehabilitation Counseling Bulletin, Vol. 46 No. 3, pp. 130-137, doi: 10.1177/00343552030460030101.

Gill, P., Stewart, K., Treasure, E. and Chadwick, B. (2008), "Methods of data collection in qualitative research: interviews and focus groups", British Dental Journal, Vol. 204 No. 6, pp. 291-295.

Glynn, M.A. and Watkiss, L. (2020), "Of organizing and sensemaking: from action to meaning and back again in a half-century of Weick's theorizing", Journal of Management Studies, Vol. 57 No. 7, pp. 1331-1354.

Greene, C.N. (1989), "Cohesion and productivity in work groups", Small Group Behavior, Vol. 20 No. 1, pp. $70-86$.

Hughes, C. (2016), "Using diversity intelligence for an inclusive organization", Talent Development, Vol. 70 No. 6, pp. $76-77$.

Inge, K.J. (2006), "Customized employment: a growing strategy for facilitating inclusive employment", Journal of Vocational Rehabilitation, Vol. 24 No. 3, pp. 191-193.

Langley, A., Smallman, C., Tsoukas, H. and Van de Ven, A. (2013), "Process studies of change in organization and management: unveiling temporality, activity, and flow", Academy of Management Journal, Vol. 56, pp. 1-13.

Lindsay, S., Cagliostro, E., Albarico, M., Mortaji, N. and Karon, L. (2018), "A systematic review of the benefits of hiring people with disabilities", Journal or Occupational Rehabilitation, Vol. 28, pp. 634-655, doi: 10.1007/s10926-018-9756-z. 
Maxwell, J.A. (1996), Qualitative Research Design: An Interactive Approach, Sage Publications, Thousand Oaks, CA.

Mikkelsen, E.N., Gray, B. and Petersen, A. (2020), "Unconscious processes of organizing: intergroup conflict in mental health care", Journal of Management Studies, Vol. 0 No. 1, pp. 1-29.

Miles, M.B. and Huberman, A.M. (1994), Qualitative Data Analysis: An Expanded Sourcebook, 2nd ed., Sage Publications, Thousand Oaks, CA.

Padkapayeva, K., Posen, A., Yazdani, A., Buettgen, A., Mahood, Q. and Tompa, E. (2017), "Workplace accommodations for persons with physical disabilities: evidence synthesis of the peer-reviewed literature”, Disability and Rehabilitation, Vol. 39 No. 21, pp. 2134-2147, doi: 10.1080/09638288. 2016.1224276.

Patriotta, G. (2016), "What inspires the academy: book reviews and beyond”, Academy of Management Review, Vol. 41, pp. 557-570.

Rimanoczy, I. and Pearson, T. (2010), "Role of HR in the new world of sustainability", Industrial and Commercial Training, Vol. 42 No. 1, pp. 11-17.

Tompa, E., Mofidi, A., Jetha, A., Lahey, P. and Buettgen, A. (2021), "Development and implementation of a framework for estimating the economic benefits of an accessible and inclusive society", Equality, Diversity and Inclusion, Vol. ahead-of-print No. ahead-of-print, doi: 10.1108/EDI-072020-0186.

Tsoukas, H., Patriotta, G., Sutcliffe, K.M. and Maitlis, S. (2020), "On the way to ithaka [1]: commemorating the 50th anniversary of the publication of Karl E. Weick's the social psychology of organizing", Journal of Management Studies, Vol. 57 No. 7, pp. 1315-1330.

United States Bureau of Labor Statistics (2020), "Persons with a disability: labor force characteristics summary - 2019", available at: https://www.bls.gov/news.release/disabl. nr0.htm\#: :text=(80. 7\%20percent).-(See\%20table \%204.),for \%20those \% 20without\%20a\%20disability (accessed: 24 September 2020).

Weick, K. (1979), The Social Psychology of Organizing, Addison-Wesley Publishing Company, Reading, MA.

Weick, K.E. (2005), "The experience of theorizing: sensemaking as topic and resource”, in Smith, K.G. and Hitt, M.A. (Eds), Great Minds in Management: the Process of Theory Development, Oxford University Press, Oxford, pp. 394-413.

\section{Corresponding author}

Chase Ochrach can be contacted at: ochrach@wisc.edu

For instructions on how to order reprints of this article, please visit our website:

www.emeraldgrouppublishing.com/licensing/reprints.htm

Or contact us for further details: permissions@emeraldinsight.com 